\title{
Effect of Seeding Rate and Seed Treatment Fungicides on Agronomic Performance, Fusarium Head Blight Symptoms, and DON Accumulation in Two Winter Wheats
}

\author{
A. W. Schaafsma and L. Tamburic-Ilincic, Department of Plant Agriculture, Ridgetown College, University of \\ Guelph, Ridgetown, Ontario, Canada NOP 2C0
}

\begin{abstract}
Schaafsma, A. W., and Tamburic-Ilincic, L. 2005. Effect of seeding rate and seed treatment fungicides on agronomic performance, Fusarium head blight symptoms, and DON accumulation in two winter wheats. Plant Dis. 89:1109-1113.

Fusarium head blight (FHB), caused by Fusarium graminearum, is an important disease of wheat (Triticum aestivum). FHB reduces yield and quality, and the pathogen produces several toxins in the grain, the most important being deoxynivalenol (DON). In North America, the foliar fungicide tebuconazole is used to reduce FHB symptoms and DON accumulation. Because of the narrow window required for its application, uniform flowering of wheat is important. The objective of this study was to investigate the influence of variety, seeding rate, and seed treatment fungicides on the flowering period of winter wheat and their effect on FHB symptoms and DON accumulation. The seed of two winter wheat varieties (Pioneer 25W60 and Pioneer 25R57) was treated with Dividend XL (difeconazole+metalaxyl), Vitaflo 280 (thiram+ carbathiin), Raxil (tebuconazole), and Baytan 30 (triadimenol) and planted at 320, 480, and 640 seeds per $\mathrm{m}^{2}$ for each treatment at Ridgetown, ON, Canada in 2000 and 2001. The plots were sprayed with tebuconazole at $50 \%$ anthesis and inoculated with $F$. graminearum 3 days later. Increased seeding rate increased the number of emerged plants, tillers, spikes per $\mathrm{m}^{2}$, and yield. All seed treatments, compared to nontreated controls, increased plant emergence and number of spikes per $\mathrm{m}^{2}$, and all except tebuconazole increased tillering and yield. Increased seeding rate decreased the length of flowering period. As flowering period increased, FHB index and DON level decreased, suggesting that greater infection was linked to more uniform flowering.
\end{abstract}

Fusarium head blight (FHB), caused by Fusarium graminearum (Schwabe) (teleomorph: Gibberella zeae Schw. (Petch)), is an important disease of wheat (Triticum aestivum L.). FHB reduces yield and quality, and $F$. graminearum produces important mycotoxins in the grain such as deoxynivalenol (DON) (3). Losses in Ontario wheat production were more than CAD\$100 million in 1996 (14). The main strategy to control FHB in Ontario is through the deployment of resistant varieties. Other tools, such as crop rotation, forecasting epidemics, fungicide application, and modified harvesting and cleaning strategies are also recommended $(14,16)$. Wheat is most susceptible to infection during the time from flowering to early dough stage (20), and the risk of a FHB epidemic is greatest when warm weather and high humidity or rainfall correspond with this period (8). Some foliar fungicides reduce FHB incidence and DON level (12), while others (7), including azoxystrobin, increased DON level. Lower FHB symptoms, percent Fusarium dam-

Corresponding author: A. W. Schaafsma

E-mail: aschaafs@ridgetownc.uoguelph.ca

Accepted for publication 18 May 2005.

DOI: 10.1094/PD-89-1109

(C) 2005 The American Phytopathological Society aged kernels (FDK), and DON level were reported when tebuconazole (Folicur) applications were made in winter wheat compared to an unsprayed control (15). In some years, foliar fungicide sprays have no economic value in winter wheat in Ontario because cultivar, weather, and other variables affect yield responses to fungicides (18). There are two fungicides applied at anthesis available for use against FHB in Canada: tebuconazole (Folicur, Bayer Crop Science) and chlorothalonil (Bravo, Syngenta Crop Protection). Tebuconazole is a systemic foliar fungicide. In North America, tebuconazole has been shown to reduce up to $50 \%$ of FHB symptoms and DON accumulation when applied at peak anthesis and with good spike coverage $(11,14)$. In addition, tebuconazole was reported to be the most effective fungicide against FHB in Europe (12). Because the most effective application of tebuconazole is when wheat is at $50 \%$ anthesis, uniform flowering of wheat is important.

Management practices such as fungicides and seeding rate play an important role in wheat production (5). Plant density is also an important factor in wheat production because it can be controlled (9). Seed treatment in wheat is used to manage seed- and soil-borne pathogens, increase winter survival, promote tillering, and increase seed viability (4). By manipulating some of these agronomic practices, it was hoped that the flowering period could be made more uniform, thereby improving the timing of application of fungicides for optimum FHB control.

The objective of this study was to investigate the influence of wheat variety, seeding rate, and seed treatment fungicides on the uniformity of flowering to improve the performance of tebuconazole for FHB control and reduction in DON accumulation.

\section{MATERIALS AND METHODS}

Certified seed of two winter wheat varieties (Pioneer 25W60, highly susceptible to FHB, and Pioneer 25R57, moderately susceptible to FHB) were treated with either Dividend XL (difeconazole+ metalaxyl, 38.3+3.2 g a.i./liter; Syngenta Crop Protection), Vitaflo 280 (thiram+ carbathiin, $130+150 \mathrm{~g}$ a.i./liter; Bayer

Table 1. Minimum, mean (SE), and maximum values for the number of emerged plants $/ 2 \mathrm{~m}$ row, number of tillers $/ 2 \mathrm{~m}$ row, number of spikes per $\mathrm{m}^{2}$, length of flowering period (days), yield (t/ha), FHB index (\%), and DON accumulation (ppm) in winter wheat, Ridgetown, $\mathrm{ON}$, 2000-2001 and 2001-2002

\begin{tabular}{lcl}
\hline Traits & 2000-2001 & 2001-2002 \\
\hline Number of emerged plants $(2 \mathrm{~m})$ & \\
Minimum & 62.0 & 85.0 \\
Mean (SE) & $121.0(7.0)$ & $151.8(7.3)$ \\
Maximum & 181.0 & 221.0 \\
Number of tillers & $(2 \mathrm{~m})$ & \\
Minimum & 44.0 & 75.0 \\
Mean (SE) & $95.7(6.0)$ & $141.5(7.7)$ \\
Maximum & 167.0 & 221.0 \\
Number of spikes per $\mathrm{m}^{2}$ & \\
Minimum & 248.0 & 224.0 \\
Mean (SE) & $395.9(15.6)$ & $424.1(22.8)$ \\
Maximum & 601.0 & 657.0 \\
Length of flowering (days) & \\
Minimum & 11.0 & 8.0 \\
Mean (SE) & $12.6(0.2)$ & $10.0(0.2)$ \\
Maximum & 15.0 & 12.0 \\
Yield (t/ha) & & \\
Minimum & 1.5 & 2.2 \\
Mean (SE) & $2.3(0.1)$ & $2.6(0.1)$ \\
Maximum & 3.1 & 3.4 \\
FHB index & & \\
Minimum & 3.5 & 10.3 \\
Mean (SE) & $7.4(0.4)$ & $20.9(1.2)$ \\
Maximum & 11.3 & 37.7 \\
DON accumulation & & \\
Minimum & 0.6 & 8.6 \\
Mean (SE) & $1.6(0.1)$ & $16.4(0.7)$ \\
Maximum & 2.6 & 25.9 \\
\hline
\end{tabular}

${ }^{a}$ Fusarium head blight $(\mathrm{FHB})$ index $=$ incidence* severity/100.

b Deoxynivalenol (DON) accumulation. 
Crop Science), Raxil (tebuconazole $1.5 \mathrm{~g}$ a.i./liter; Bayer Crop Science), or Baytan 30 (triadimenol 30\% wt/wt; Bayer Crop Science) and planted at 320, 480, and 640 seeds per $\mathrm{m}^{2}$ for each treatment at Ridgetown, ON, in mid-October in 2000 and 2001. The experiments were arranged in a factorial randomized complete block design with four replications. Plots were six rows, planted at a row spacing of $17.8 \mathrm{~cm}$, and $4 \mathrm{~m}$ in length. The seed was treated in individual 750-g lots in plastic bags, and the inflated bags were rolled until all seed was thoroughly covered with chemical. Nontreated seed was used as a control. The number of emerged plants was counted for each treatment in fall 2000 and 2001 from 2 rows $1 \mathrm{~m}$ in length, while the number of tillers (shoots that survived winter) was counted in the following spring from the sections of the same rows. The length of flowering period (recorded as total number of days when wheat spikes showed anthers) and number of wheat spikes per $\mathrm{m}^{2}$ were counted for each treatment.

Each year the entire experiment was sprayed once on the same day with fungicide. The single spray timing was chosen based on an estimate of $50 \%$ anthesis (Zadoks growth stage, ZGS $65 ; 21$ ) in the primary heads across the experiment. Both varieties flowered at a similar time. The Folicur 432 F (tebuconazole, 432 g a.i./liter, Bayer Crop Science) spray application was made at $290 \mathrm{ml} / \mathrm{ha}$ using a backpack precision sprayer on individual plots. The sprayer had a 1-m boom fitted with 2 twin jet nozzles, spaced at $50 \mathrm{~cm}$, operated at $240 \mathrm{kPa}$ and delivering 240 liters/ha. Each plot was inoculated with a 100-ml suspension of macroconidia from a mixture of four $F$. graminearum isolates (DAOM 178148, DAOM 234041, DAOM 234042, and DAOM 234043, from the Canadian collection of fungal cultures in Ottawa) at 50,000 macroconidia per $\mathrm{ml} 3$ days following treatment with fungicide.

Plots were misted daily beginning when they were inoculated. The overhead mister operated at one 8-s burst every minute from 1000 to $1600 \mathrm{~h}$ each day, delivering about $7.5 \mathrm{~mm}$ of water daily. The mist system was engaged for 7 days after inoculation. Ten wheat heads were selected by grabbing a handful of stems without looking and counting the first 10, from each corner and in the middle of each plot for a total of 50 heads per plot, when the early dough stage of the crop was reached (ZGS 83). FHB index calculated on these heads
A

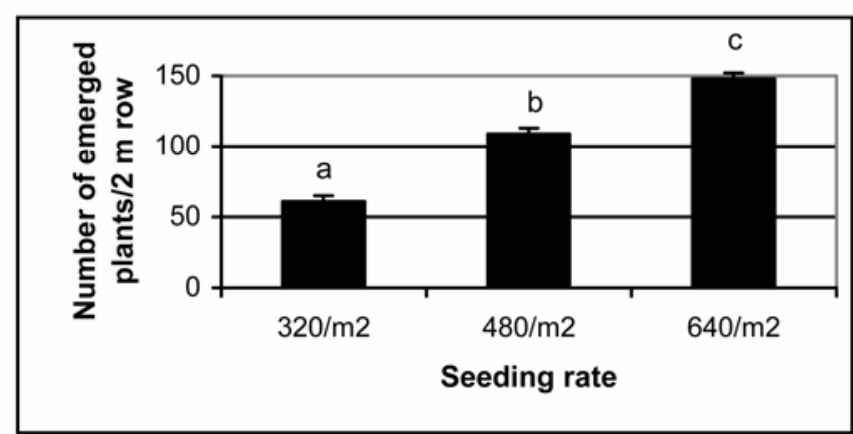

B

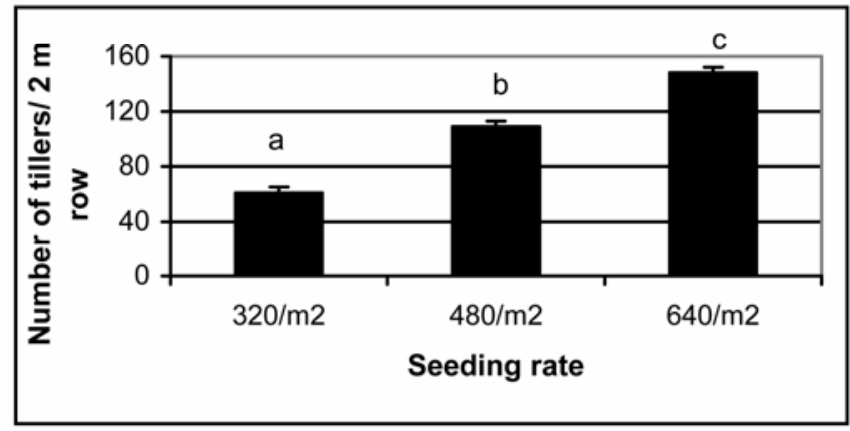

C

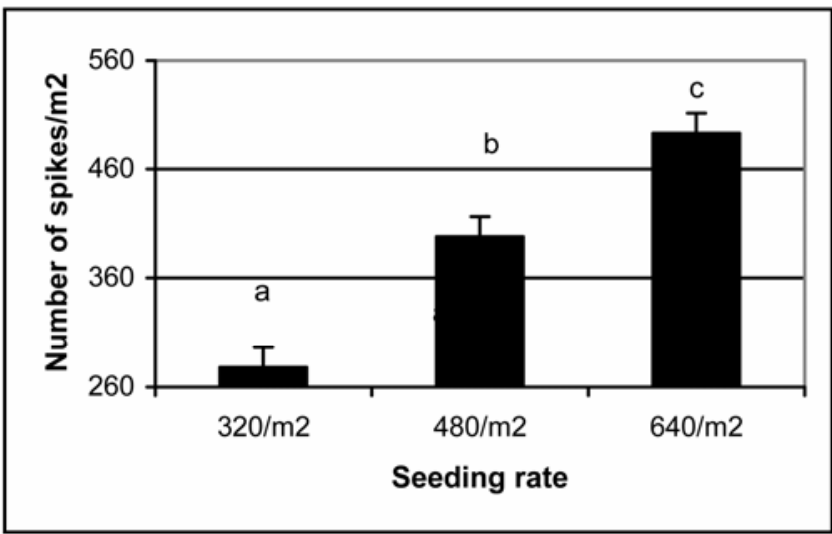

D

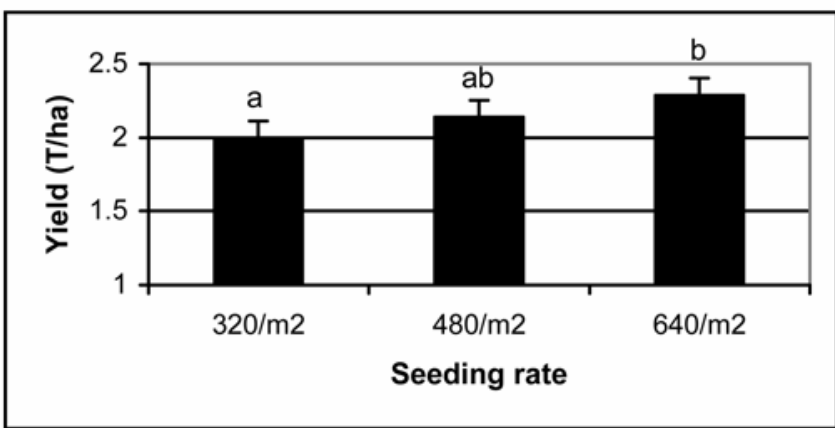

E

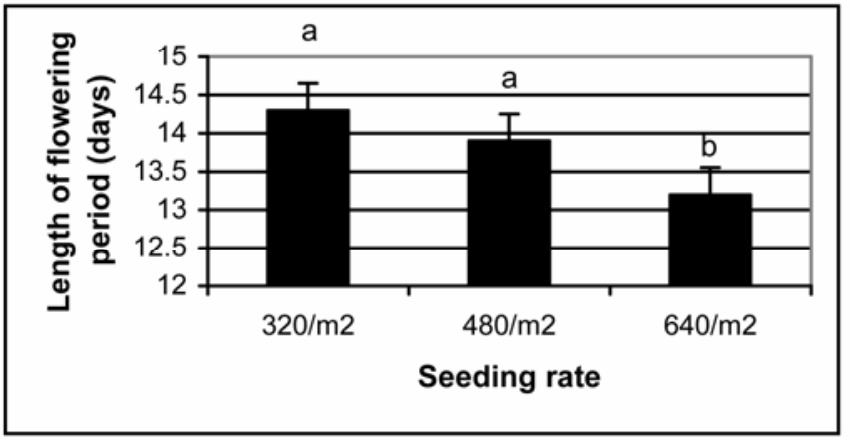

Fig. 1. Effect of seeding rate on $\mathbf{A}$, number of emerged plants $/ 2 \mathrm{~m}$ row $( \pm \mathrm{SE}), \mathbf{B}$, number of tillers $/ 2 \mathrm{~m} \mathrm{row}( \pm \mathrm{SE}), \mathbf{C}$, number of spikes per $\mathrm{m}^{2}( \pm \mathrm{SE}), \mathbf{D}$, yield (t/ha) $( \pm$ SE), and E, length of flowering period $( \pm$ SE) of winter wheat in Ridgetown, ON, in 2000-2001 and 2001-2002. Means followed by the same letter are not different according to Fisher's protected least significant difference $(P=0.05)$. 
as incidence (percent heads infected) $\times$ severity (percent spikelets infected) $/ 100$.

The plots were harvested at maturity, in mid-July in 2001 and 2002, and the yields were corrected to $14 \%$ moisture. The grain from a 20-g subsample was ground through a ROMER mill (Model 2A, Romer Labs Inc., Union, MO). DON was extracted from the grounded subsample in $100 \mathrm{ml}$ of methanol and water (1:9) and quantified using an enzyme-linked immunosorbent assay (ELISA) (17) with a limit of detection of $0.2 \mathrm{ppm}$ using a commercial kit available from Diagnostix (available online).

Statistical analysis. PROC UNIVARIATE test (2003. SAS Institute, Cary, NC) was used to test the assumptions of ANOVA. The parameters measured were normalized by transformation if necessary. The data were analyzed using PROC MIXED (SAS Institute) where year effects were random. PROC MIXED was used because it recognizes and accounts for year effects as significant and random, allowing an overview of the fixed effects of seed rate, seed treatment, and variety, in the absence of the random effects. ANOVA was done on the means of four replications for each treatment combination for each year. All sources of variation (seed treatment, variety, and seed rate) and their interactions were included in the full model. All nonsignificant $(P>0.05)$ effects were then removed stepwise from the full model. A correlation (PROC CORR) between FHB symptoms and DON accumulation was calculated using a Pearson's correlation coefficient (SAS Institute). The level of significance used for statistical analyses was $P=0.05$ unless otherwise stated.

\section{RESULTS AND DISCUSSION}

All the parameters measured were normally distributed with the exception of FHB symptoms and DON accumulation, which were transformed by $\operatorname{sqrt}(x+1)$ and $\ln (x+0.5)$, respectively. Mean values for the number of emerged plants, number of tillers, number of spikes per $\mathrm{m}^{2}$, length of flowering, yield, FHB symptoms, and DON accumulation are shown in Table 1.

Seeding rate. The recommended seeding rate for winter wheat in Ontario is between 350 and 450 seeds per $\mathrm{m}^{2}$ (13). In our study, each increment in seeding rate increased the number of emerged plants, tillers, and spikes per $\mathrm{m}^{2}$, and yield (Fig. 1). Our results agree with those of Lloveras et al. (9), who reported that the number of spikes per $\mathrm{m}^{2}$ and yield increased with increased seeding densities.

Increased seeding rate significantly reduced the flowering period (Table 2), but by only 1 day (Fig. 1E). Geleta et al. (5) reported that lower seeding rates delayed flowering by up to 2 days. Seeding rates affected FHB (Fig. 2); however, the effect interacted with seed treatment (Table 2). Taken alone, the control plots indicate that there might be some optimum spike density between 300 and 700 seeds per $\mathrm{m}^{2}$, where FHB is minimized, perhaps by a modified environment in the canopy. However, the pattern of response was variable across the different seed treatments (Fig. 2). In the present study, seeding rate did not affect DON levels (Table 2).

Seed treatment fungicides. There were significantly more emerged plants and spikes per $\mathrm{m}^{2}$ in seed-treated plots (Fig. 3A and C). Gilbert and Tekauz (6) also reported that fungicide seed treatments improved emergence. These seed treatments are meant to protect against seed- or soilborne pathogens, as suggested by Argyris et al. (1). However, we did not take note which pathogens were responsible. Emergence was greatest after treatment with Vitaflo 280 (thiram+carbathiin), which agrees with Martin and Johnston (10), who reported that Vitaflo 280 significantly increased germination in spring wheat. In addition, all seed treatments with the exception of Raxil (tebuconazole), compared to nontreated controls, increased the number of tillers (Fig. 3B). The results from the present study agree with Gaska (4), who reported that

Table 2. Analysis of variance (reduced model) for seed treatment, wheat variety, seed rate and their interactions on: a) number of emerged plants $/ 2 \mathrm{~m}$ row, b) number of tillers $/ 2 \mathrm{~m}$ row, c) number of spikes per $\mathrm{m}^{2}$, d) yield ( $\mathrm{t} / \mathrm{ha}$ ), e) length of flowering period (days), f) FHB index (\%), and g) DON accumulation (ppm) in winter wheat, Ridgetown, ON, 2000-2001 and 2001-2002

\begin{tabular}{|c|c|c|c|c|}
\hline Source $^{a}$ & $\mathbf{N D F}^{\mathbf{b}}$ & $\mathbf{D D F}^{\mathbf{b}}$ & $\boldsymbol{F}$ & $P>F$ \\
\hline \multicolumn{5}{|c|}{ a) Number of emerged plants $/ 2 \mathrm{~m}$ row } \\
\hline Seed treatment & 4 & 51 & 7.66 & $<0.0001$ \\
\hline Variety & 1 & 51 & 3.85 & 0.0551 \\
\hline Seed rate & 2 & 51 & 254.84 & $<0.0001$ \\
\hline \multicolumn{5}{|l|}{ b) Number of tillers $/ 2 \mathrm{~m}$ row } \\
\hline Seed treatment & 4 & 51 & 6.17 & 0.0004 \\
\hline Seed rate & 2 & 51 & 102.78 & $<0.0001$ \\
\hline \multicolumn{5}{|l|}{ c) Number of spikes per $\mathrm{m}^{2}$} \\
\hline Seed treatment & 4 & 51 & 2.45 & 0.0582 \\
\hline Seed rate & 2 & 51 & 72.82 & $<0.0001$ \\
\hline \multicolumn{5}{|l|}{ d) Yield (T/ha) } \\
\hline Seed treatment & 4 & 51 & 2.38 & 0.0636 \\
\hline Seed rate & 2 & 51 & 3.94 & 0.0256 \\
\hline \multicolumn{5}{|c|}{ e) Length of flowering period (days) } \\
\hline Seed rate & 2 & 51 & 5.64 & 0.0061 \\
\hline \multicolumn{5}{|l|}{ f) FHB index ${ }^{c}$} \\
\hline Variety & 1 & 43 & 25.87 & $<0.0001$ \\
\hline Seed treatment*seed rate & 8 & 43 & 2.35 & 0.0341 \\
\hline \multicolumn{5}{|l|}{ g) DON content $(\mathrm{ppm})^{\mathrm{d}}$} \\
\hline Variety & 1 & 51 & 41.89 & $<0.0001$ \\
\hline
\end{tabular}

${ }^{\text {a }}$ Effects of source variables were fixed; 2 years were the random effect in SAS PROC MIXED.

${ }^{\mathrm{b}} \mathrm{NDF}=$ degrees of freedom in the numerator; $\mathrm{DDF}=$ degrees of freedom in the denominator.

c Fusarium head blight (FHB) index $=$ incidence* severity/100 was transformed using $\operatorname{sqrt}(x+1)$.

d Deoxynivalenol (DON) content was transformed using $\ln (x+0.5)$.

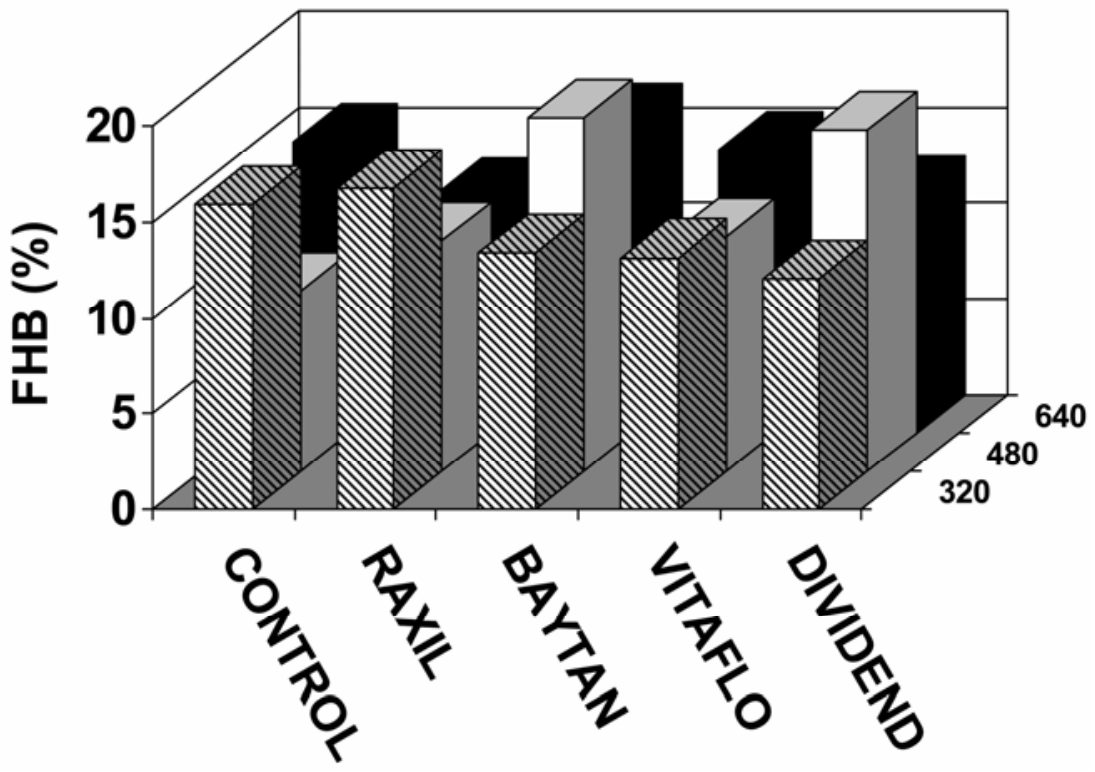

Fig. 2. Effect of seeding rate $\left(320,480\right.$, and 640 seeds per $\left.\mathrm{m}^{2}\right)$ and seed treatment on Fusarium head blight (FHB) index of winter wheat in Ridgetown, ON, in 2000-2001 and 2001-2002. 


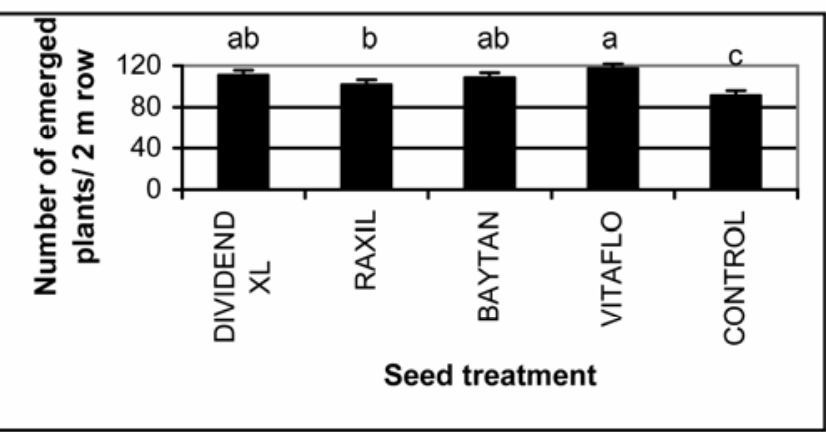

B

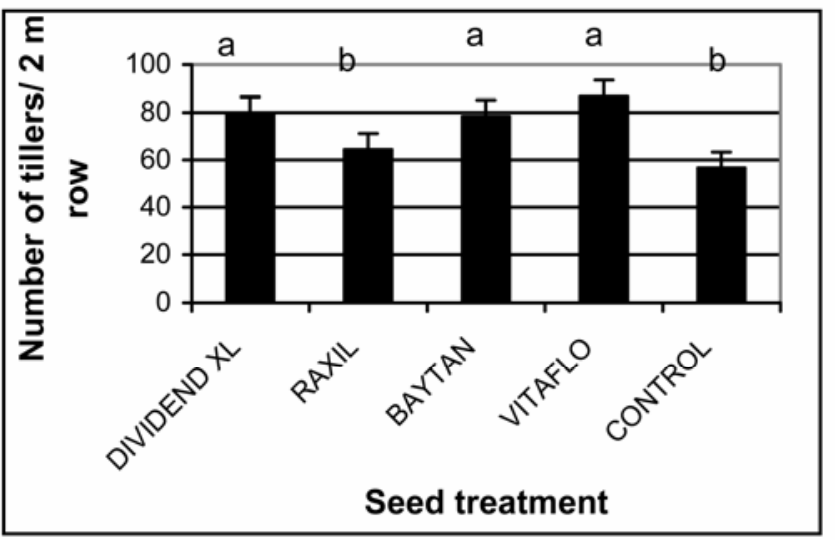

$c$

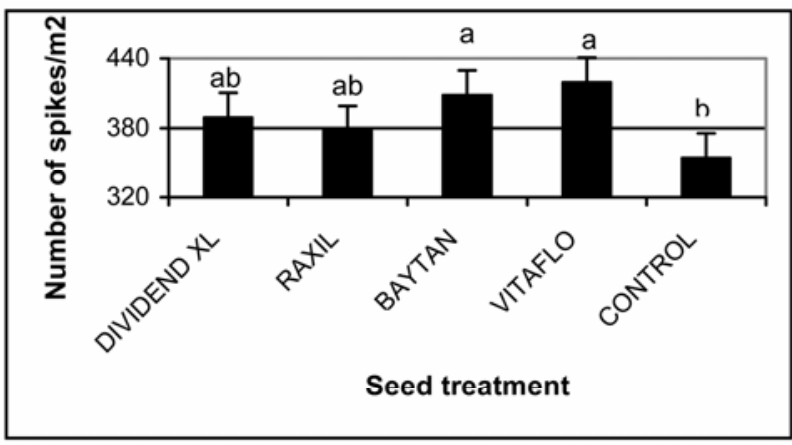

D

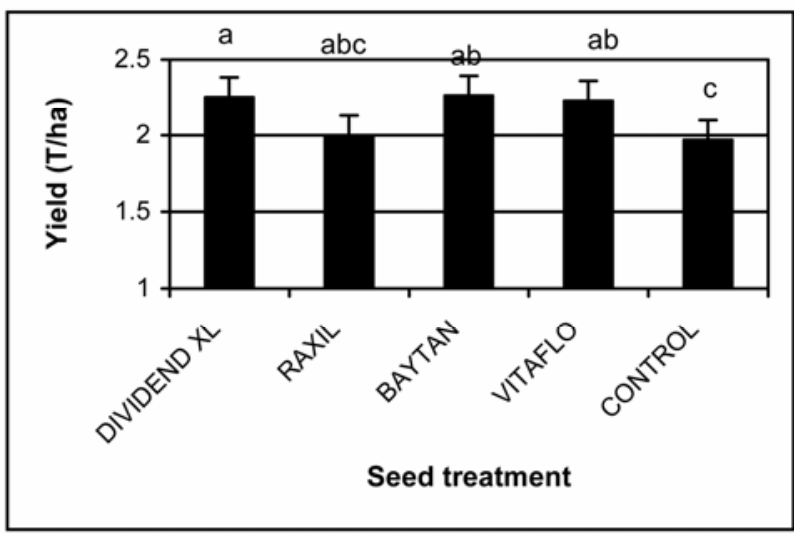

Fig. 3. Effect of seed treatment on $\mathbf{A}$, number of emerged plants $/ 2 \mathrm{~m}$ row $( \pm \mathrm{SE}), \mathbf{B}$, number of tillers $/ 2 \mathrm{~m}$ row $( \pm \mathrm{SE})$, $\mathbf{C}$, number of spikes per m ${ }^{2}( \pm \mathrm{SE})$, and D, yield (t/ha) $( \pm$ SE) of winter wheat in Ridgetown, ON, in 2000-2001 and 2001-2002. Means followed by the same letter are not different according to Fisher's protected least significant difference $(P=0.05)$.

seed treatments in wheat increased winter survival and promoted tillering.

Of the seed treatments, Raxil (tebuconazole) resulted in the fewest plants, tillers, and spikes (Fig. 3). All seed treatments significantly increased yield compared to nontreated controls, with the exception of Raxil (tebuconazole) (Fig. 3D). Although we did not record the presence of foliar diseases such as powdery mildew (Blumeria graminis f. sp. tritici) and leaf rust (Puccinia triticina), it is expected that the foliar application of Folicur (tebuconazole) decreased their influence and had a positive influence on grain yield across treatments.

There was an interaction between seed treatment and seeding rate affecting FHB symptoms (Table 2). Raxil resulted in a consistently lower FHB index at increased seeding rates (Fig. 2), which may be a reflection of a more stable canopy density as seeding rate increased. With Baytan and Vitaflo, the FHB index increased with increased seeding rate. The other seed treatments tended to result in a higher level of FHB (Fig. 2), and these were also the ones with higher plant densities. Improving emergence and tillering, therefore, may increase plant canopy density, favoring plant diseases like FHB. It is difficult to determine whether the increased infection level is biologically meaningful, because there was no uniform pattern across the seed treatments applied (Fig. 2). In con- trast, Teich and Hamilton (19) reported that FHB symptoms were reduced when wheat seed was treated with Vitaflo 280. Overall, seed treatment did not affect the length of flowering period or DON accumulation (Table 2).

Variety. Overall, the variety Pioneer 25R57 had more emerged plants than Pioneer 25W60 (Fig. 4A). An interaction between seeding rate and wheat variety was reported for tiller production (2). In the present study, there was no interaction between seeding rate and wheat variety on the number of emerged plants (Table 2); however, only two varieties were included in the experiment. Variety also had no effect on the number of tillers, spike production, length of flowering period, or yield (Table 2). In the present study, a highly and a moderately FHB susceptible variety were used. Argyris et al. (1) reported that even the wheat varieties with Type II (spread within spike) FHB resistance did not affect seed germination and vigor.

As expected, given the relative susceptibility of the two wheat varieties to FHB, the variety Pioneer 25R57 had significantly lower FHB symptoms (Fig. 4B) and DON content than Pioneer 25W60 (Fig. 4C). The correlation between FHB symptoms and DON accumulation after foliar application of tebuconazole and inoculation with $F$. graminearum was high ( $r=$ $0.91, P=<0.001)$. This correlation is much higher than those we normally observe ( $r=$ 0.18 to 0.70 ) in inoculated nurseries designed to evaluate FHB resistance in wheat cultivars or breeding lines (unpublished data). We assume that a high correlation in the present study existed because of the genotypic uniformity in the experiments with only two winter wheat varieties used. Furthermore, the uniformity may have been enhanced by the application of tebuconazole across all treatments.

We expected that increasing the seeding rate would result in more uniform flowering of wheat, presenting more heads at the optimum stage for treatment, thereby improving the performance of tebuconazole for FHB control. However, the plots were also inoculated when the majority of the heads were at the optimum stage for infection. This increased the likelihood of infection in plots with more heads at the most susceptible stage, i.e., those plots with a shorter, more compact flowering period. Flowering period and FHB and DON were negatively correlated $(r=-0.56$ and -0.68 $[P=<0.0001]$, for FHB and DON, respectively). That is, as the flowering period shortened, FHB and DON increased, suggesting that the risk of increased infection with a more uniform flowering period is perhaps greater than the potential benefit derived from treating more heads that are at the optimum stage for treatment with tebuconazole. The variation in flowering 
A

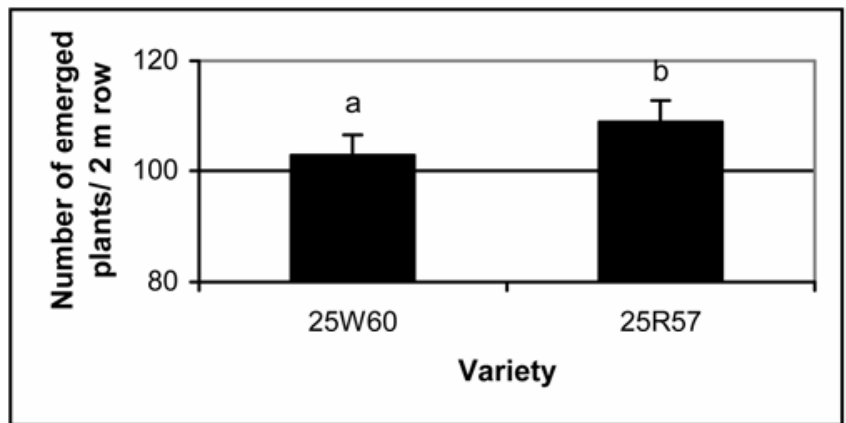

B

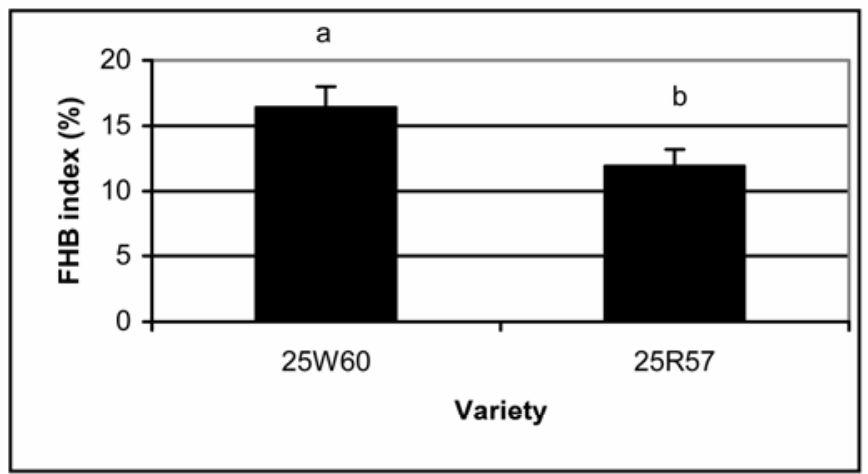

C

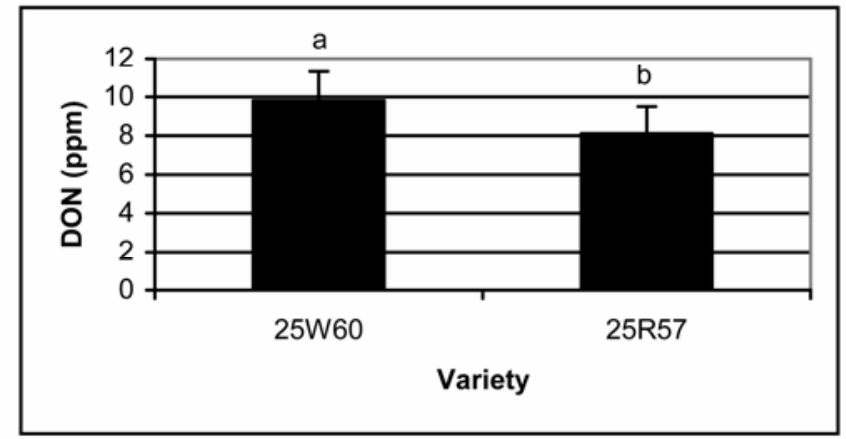

Fig. 4. Effect of variety on $\mathbf{A}$, number of emerged plants $/ 2 \mathrm{~m}$ row $( \pm \mathrm{SE}), \mathbf{B}$, Fusarium head blight (FHB) index $( \pm \mathrm{SE})$, and $\mathbf{C}$, deoxynivalenol (DON) accumulation (ppm) in mature grain $( \pm \mathrm{SE})$ of winter wheat in Ridgetown, ON, in 2000-2001 and 2001-2002. Means followed by the same letter are not different according to Fisher's protected least significant difference $(P=0.05)$.

period was observed in relatively small and uniform plots. We expect the effect in large fields to be much greater, relating to topography and other edaphic factors, making it difficult to predict the outcome of a similar, larger study in commercial fields. Additional research is needed to determine the effect of seeding rate and seed treatment fungicide on FHB symptoms and DON content under natural infection, at different locations over a range of wheat varieties and in larger fields. Furthermore, the increased risk of greater infection with more uniform flowering must be weighed against the potential benefit of treating more wheat heads at the optimum time, especially when fungicides such as tebuconazole are not $100 \%$ effective. As improvements are made in fungicide chemistry and application technology, the risk balance may tip in favor of better-timed fungicides.

\section{ACKNOWLEDGMENTS}

This project was funded by partnership between the Canadian Adaptation Council (CanAdapt), the Ontario Wheat Producers Marketing Board, Bayer Crop Science, Syngenta Crop Protection, BASF, the Ontario Ministry of Agriculture and Food, Pioneer Hi-Bred Canada, and the University of Guelph. Technical assistance by Diane Paul, Mila Vujevic, and Todd Phibbs is gratefully acknowledged. We thank the two anonymous reviewers for their helpful suggestions of ways to improve the manuscript.

\section{LITERATURE CITED}

1. Argyris, J., Van Sanford, D., and TeKrony, D. 2003. Fusarium graminearum infection during wheat seed development and its effect on seed quality. Crop Sci. 43:1782-1788.

2. Carr, P. M., Horsley, R. D., and Poland, W. W. 2003. Tillage and seeding rate effects on wheat cultivars: II. Yield components. Crop Sci. 43:210-218.

3. Dexter, J. E., Marachylo, B. A., Clear, R. M., and Clarke, J. M. 1997. Fusarium head blight: Effect on semolina and pasta-making quality of durum wheat. Cereal Chem. 74:519-525.

4. Gaska, J. 2000. Efficacy of seed treatment fungicides for winter wheat in Wisconsin Wisconsin Crop Improvement Association. 2000 Annual Meeting.

5. Geleta, B., Atak, M., Baenziger, P. S., Nelson, L. A., Baltenesperger, D. D., Eskridge, K. M. Shipman, M. J., and Shelton, D. R. 2002. Seeding rate and genotype effect on agronomic performance and end-use quality of winter wheat. Crop Sci. 42:827-832.

6. Gilbert, J., and Tekauz, A. 1995. Effects of fusarium head blight and seed treatment on germination, emergence, and seedling vigour of spring wheat. Can. J. Plant Pathol. 17:252-259.

7. Hart, P., and Ward, R. 1997. Efficacy of fungicides on Fusarium head blight severity and levels of vomitoxin. Pages 40-41 in: Proc. National Fusarium Head Blight Forum, St. Paul, MN.

8. Hooker, D. C., Schaafsma, A. W., and Tamburic-Ilincic, L. 2002. Using weather variables pre- and post-heading to predict deoxynivalenol content in winter wheat. Plant Dis. 86:611-619.

9. Lloveras, J., Manent, J., Viudas, J., López, A., and Santiveri, P. 2004. Seeding rate influence on yield and yield components of irrigated winter wheat in a Mediterranean climate. Agron. J. 96:1258-1265.

10. Martin, R., and Johnston, H. W. 1982. Effects and control of fusarium disease of cereal grains in Atlantic Provinces. Can. J. Plant Pathol. 4:210-216.

11. McMullen, M., Jones, R., and Gallenberg, D. 1997. Scab of wheat and barley: A re-emerging disease of devastating impact. Plant Dis. 81:1340-1348.

12. Mesterhazy, A., and Bartok, T. 1996. Control of Fusarium head blight of wheat by fungicides and its effect on the toxin contamination of the grains. Pflanzenschutz-Nachr. Bayer 49:181-198.

13. OMAF. 2002. Agronomy guide for field crops. Publ. 811. T. Baute, ed. Queens Printer, Toronto, Canada.

14. Schaafsma, A. W. 2002. Economic changes imposed by mycotoxins in food grains: Case study of deoxynivalenol in winter wheat. Pages 271-276 in: Mycotoxins and Food Safety. J. W. DeVries, M. W. Trucksess, and L. S. Jackson, eds. Kluwer Academic/Plenum Publishers, New York.

15. Schaafsma, A., and Tamburic-Ilincic, L. 1998. Susceptibility of winter wheat varieties to Fusarium Head Blight and control by tebuconazole (FOLICUR) in artificially inoculated misted plots. Pages 53-55 in: Proc. $1998 \mathrm{Na}$ tional Fusarium Head Blight Forum. P. Hart, R. Ward, R. Bafus, and K. Bedford, eds.

16. Schaafsma, A. W., Tamburic-Ilincic, L., Miller, J. D., and Hooker, D. C. 2001. Agronomic considerations for reducing deoxynivalenol in wheat grain. Can. J. Plant Pathol. 23(3):279-285.

17. Sinha, R. C., and Savard, M. E. 1996. Comparison of immunoassay and gas chromatography methods for the detection of the mycotoxin deoxynivalenol in grain samples. Can. J. Plant Pathol. 18:233-236.

18. Sutton, J. 1985. Effectiveness of fungicides for managing foliar diseases and promoting yields of Ontario winter wheat. Phytoprotection 66:141-152.

19. Teich, A. H., and Hamilton, J. R. 1985. Effect of cultural practices, soil phosphorus, potassium, and $\mathrm{pH}$ on the incidence of Fusarium Head Blight and deoxynivalenol levels in wheat. Applied and Environmental Microbiology. Vol. 49, No. 6:1429-1431.

20. Wiese, M. V. 1987. Compendium of Wheat Diseases. 2nd ed. American Phytopathological Society, St. Paul, MN.

21. Zadoks, J. C., Chang, T. T., and Konzak, C. F. 1974. A decimal code for the growth stages of cereals. Weed Res. 14:415-421. 